\title{
Design for Cultural Heritage at the University of Ferrara
}

\author{
Anna Bernabè ${ }^{1}$, Marina Contarini ${ }^{1}$, Marco Manfra ${ }^{2}$, Davide Turrini' \\ ${ }^{1}$ University Library System, University of Ferrara, Italy; ${ }^{2}$ Department of Architecture, \\ University of Ferrara, Italy.
}

\begin{abstract}
Alongside Teaching and Research, Italian universities are also committed to Public Engagement activities featuring teaching and cultural initiatives for a non-academic audience. At the University of Ferrara, this commitment was translated into an exhibition in April 2019, originating from a virtuous union of cultural heritage and teaching activities. The creation of the "Natura Naturata" exhibition involved the synthesis of taught courses and research by the University of Ferrara's Industrial Product Design students together with their teachers, in collaboration with librarians. In the Product Design 2 Workshop, students develop exhibition projects, starting from the curatorial concept, through the construction, up to the graphic-communicative aspects and the creation of information and teaching tools. The exhibition was created based on the study of rules used to properly protect library assets so that students could gain specific skills for the preparation of bibliographic exhibitions. It took shape in the Chemistry and Life Sciences Library Santa Maria delle Grazie to emphasize the importance of the University's tangible and intangible cultural heritage with the intention of conveying the 'world' of library collections - and also the University's historical and architectural heritage - to students, scholars, and citizens.
\end{abstract}

Keywords: Cultural heritage, rare books, exhibition design, virtual exhibitions, virtual labs, education outside the classroom. 


\section{Rare books heritage at the University of Ferrara}

The city of Ferrara, with its historical Renaissance centre, is recognized by UNESCO as a world heritage site. A key part of its history is a university of ancient origin founded by a dispensation from Pope Boniface IX in 1391 to the Marquis Alberto V d'Este enabling him to establish the first courses in Arts, Theology and Jurisprudence. Today the Ferrara University is home to numerous courses of study attended by over twenty thousand students who make the city's streets vibrant and lively. The interconnection between the academic community and the city can be seen on the one hand both in the historical buildings and modern architecture of which the city's geometry consists and in which its places of study and research are hosted; on the other hand, the vitality and tradition of scholarship and knowledge for which the academic community and the University Ferrara are known, have built up scientific and cultural deposits such as the collections of rare books in the libraries which include about 10,000 books published from the mid-fifteenth century until 1830 including incunabula (books printed before 1501), sixteenth-century and seventeenth-century books, and volumes from the eighteenth and nineteenth centuries until 1830 (Università degli Studi di Ferrara, 2019).

\section{Teaching from curating to exhibition design}

These exquisite, inestimable treasures are the focal point and stimulus that serve both as research tools and teaching support in the belief that they are not merely documentary records to be conserved but also to be made accessible and introduced to a wider audience. Over the course of ten years, mapping and safeguarding these cultural deposits has been done by disinfesting, restoring and digitizing them, not to mention meticulously cataloguing every item and their characteristics as artefacts; and from 2016 onwards, teachers at the Department of Architecture have been working together with the Sistema Bibliotecario di Ateneo (University Library System) in establishing activities to promote and spread the message about the University of Ferrara's rare book collections and archival materials, having in mind not only the University's institutional users but also the interests of the wider community. Promotion was meant to increase awareness of cultural heritage and ensure the wider community through participation to round table and study days; scientific posters at national and international conferences; educational workshops and work experience projects for school students from Ferrara, with whose input we also designed a permanent touristiccultural itinerary using the historical rare collections of the University, the Libraries, the Museum System and the historical, architectural heritage of the University of Ferrara (Università degli Studi di Ferrara, 2019). Public information on all of the scientific and educational activities is complemented by video-documentaries produced with the help of the University's Center for Communication Technologies and University Innovation (se@unife). In 2017, teachers and students from the Industrial Product Design course of the 
University and the University Library System began a valuable, stimulating collaboration, which has led to the creation of innovative educational experience and cultural promotion. This experience was made possible because cultural heritage design is one of the key thematic profiles featured in the University of Ferrara's Industrial Product Design course since the course was established. This field of application has been the subject of design and project management exercises programmed into various phases of the training activities, from the workshops in the first year of study to the degree thesis. Since 2016, cultural heritage design has been taught using a very rigorous, systematic approach in the Product Design Workshop 2 where students run temporary exhibition projects, starting from the curatorial concept, through construction and fit-out, to the graphic communication aspects and the creation of analogue or digital information and teaching tools. In 2018, the Workshop operated in an exclusive collaboration with the University Library System. The students played a leading role in the research on the University's rare book collections, which involved the planning of an exhibition itinerary in the headquarters of the Chemistry and Life Sciences Library Santa Maria delle Grazie of the University of Ferrara, thus, by this choice, reaffirming the central importance of tangible and intangible heritage of the University. The result was an initiative included in the specific program of heritage communication of Ferrara's University and which is notable for its originality also at national level (Cassella, Madonna 2019).

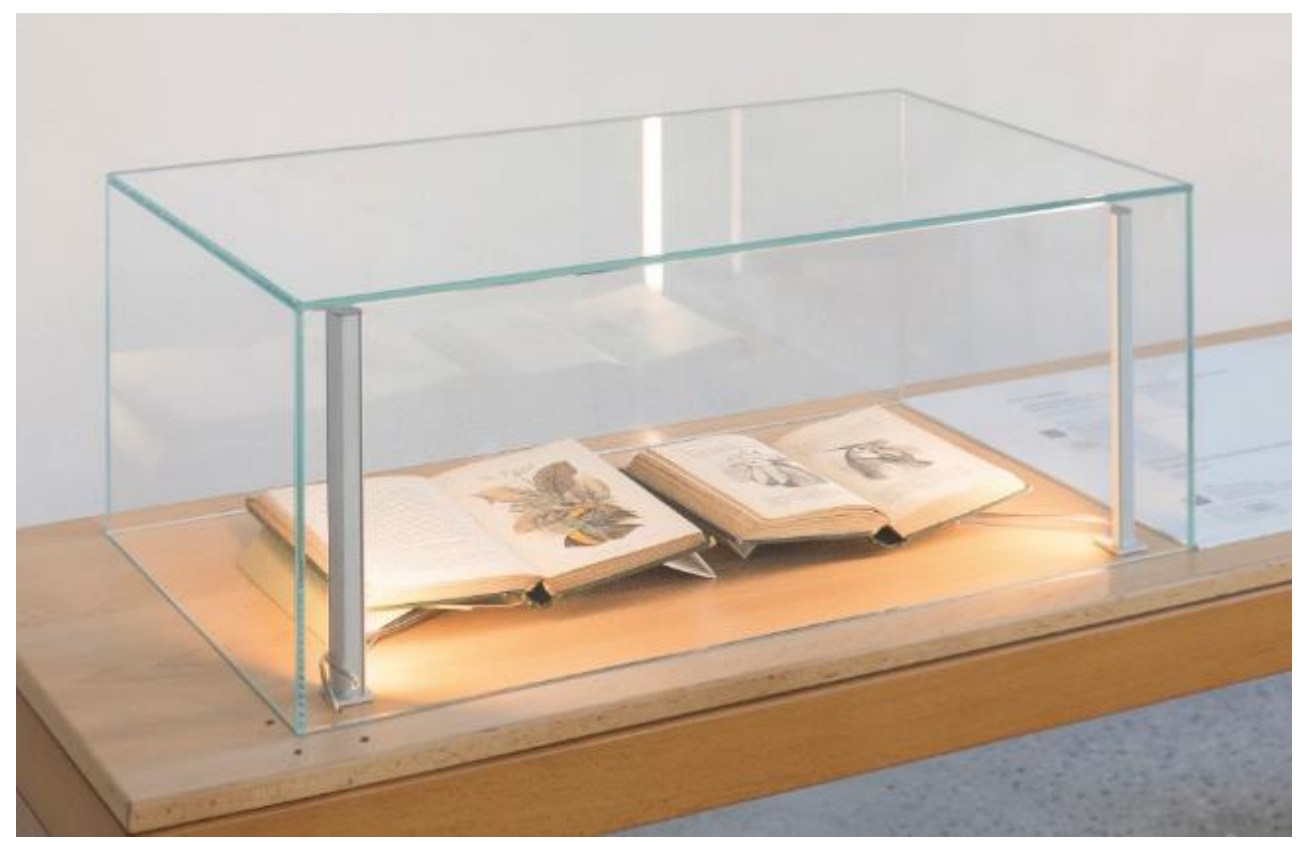

Figure 1. Natura Naturata exhibition of rare books at the University of Ferrara (2019). 


\section{The University's mission from teaching to public engagement}

Students and teachers of the Product Design Workshop 2 had been working for about one year together with the University of Ferrara's librarians in order to develop the research and teaching activities aimed at this rare book exhibition. The implemented methodology consisted of several consequent steps, such as planning, studying and carrying out activities, checking and communicating results. Therefore, the starting point was a detailed planning of the initiative, firstly stating its objectives, that were in compliance with the Italian law on cultural heritage (Ministero per i Beni e le Attività Culturali 2004) and the University's strategic goals related to its three Missions (Research, Teaching and Third Mission, the latter especially intended as Public Engagement), to which both the academic staff and the librarians must contribute. The whole project was then designed in accordance with the University of Ferrara's Rectoral Mandate Plan 2015-2021 - as regards the promotion of public goods of a social, teaching and cultural nature - and pursuing its specific Strategic Objectives 2019-2021, especially the "C.4 Consolidation and development of the Public Engagement activities" and the "H.1 Improvement of the quality and services of our libraries". Secondly, all the activities were carried out thanks to the cooperation between librarians, academics experts in several disciplines, and students with their creativity: this mix realized a co-designed project, which benefited from highly-skilled co-designers, working in the same institution and sharing identity values - as a specific asset of initiatives developed within universities. Furthermore, the partnerships with private companies, created by means of the University's existing relationships and networks, fostered the activities. Thirdly, the checking step tried to understand how and how much the initiative helped the outreach of the academic audiences (university staff and students), as well as the nonacademic ones (especially Ferrara citizens and tourists), in the perspective of Public Engagement. This assessment focused on the initiative's impact as described in ISO 16439:2014 (ISO16439 2014), i.e. the "difference or change in an individual or group resulting from the contact with library services": in this case, the "difference or change" regards the initiative's beneficial effects on the cultural and professional development of the involved audiences. A report of the initiative is going to be published online open access, and it is also supposed to be used by academics and librarians currently in charge of future planning. The project will be also submitted to the national assessment led by the Italian National Agency for the Evaluation of the University and Research System (ANVUR). In fact Italian universities' Teaching and Research activities have been assessed for over a decade by ANVUR, with reference to the quality of the processes and their results. In addition to this, in 2011 the assessment of Third Mission initiatives was introduced, as they are expression of each University's commitment to the social, cultural and economic progress of society, especially related to its local area and community (Sabba 2019; Bernabè, Tinti 2020). 


\section{Educational workshop for the exhibition}

\subsection{Actual exhibition}

Compared to the design exercises conducted by the students of the Product Design Workshop 2 in previous years, the notable innovative dimension of the course in the 2018-2019 academic year was the opportunity given to the students of the course not merely to create a virtual or theoretical exhibition narrative but to actually engage in translating it into the reality of a physical location and having to try their hand at displaying complex objects such as scientific rare books conserved in the libraries of the University of Ferrara. The first innovative dimension was the students' and their teachers' encounter with the outstanding books belonging to the collections. The encounter was mediated by the librarians who accompanied them on this voyage of discovery of the existing heritage, the aesthetic characteristics of each artefact, and its cultural and identitarian value within the academic institution. In the workshop inside the library, the students received a special tutorial on the characteristics and history of rare books and early publishing which helped them to fully appreciate and raise a greater awareness of the very special nature and beauty of the books. The professors and students focussed their attention on four collections: Botany and Human Anatomy, Earth Sciences, and Biology conserved at the Chemistry and Life Sciences library, which was also identified as a virtual space for the workshop exhibition practical exercise. The books were selected both on the basis of the aesthetic value but also by asking for them to be assessed on their scientific value and historical relevance. Identification of the disciplines to which the chosen books belong was based on the scientific interests which have characterized the history of the University of Ferrara. These have been evocatively woven together in the curation project recalling the Spinozan meaning of Natura Naturata (Nature Natured) understood as "substance expressed" in different modes and attributes of the earth and of the forms of life that populate it (Dal Buono, Trincherini, Turrini, 2019). The rare possibility of constructing an actual exhibition in the same venue as the workshop practical exercises triggered a process of executive synthesis and translation of the students' proposals, centered on the main concept of Nature as a dynamic generative entity. This is why the exhibition itinerary guided the visitor through the antiquarian books to explore the sky and the earth, and plants, animals and humankind. The second innovative dimension of the workshop approach was the choice of the place to house the exhibition: the former church of Santa Maria Delle Grazie - a convent until the beginning of the nineteenth century and then converted into the University library. The internal arrangement of the historical building of the ex-church created a wide diversity of spaces which facilitated the layout of the various sections of the exhibition and provided a valuable opportunity to extend research into, understanding of, and experimentation in the potentialities of design in promoting artistic and cultural heritage (Lupo, 2008). Another dimension of the workshop's practical exercises relates to deciding on the elements governing the exhibition's graphic design. Alongside the 
design and creation of the narrative elements of the exhibition (banners, section panels, display cases, catalogue of the rare books and of the students' projects), posters and postcards were created to promote the event As well as the work of coming up with concepts for the design of the exhibition this was also an opportunity for students to get out of the classroom and become involved personally in the construction of the exhibition with its technical aspects and logistic organization.
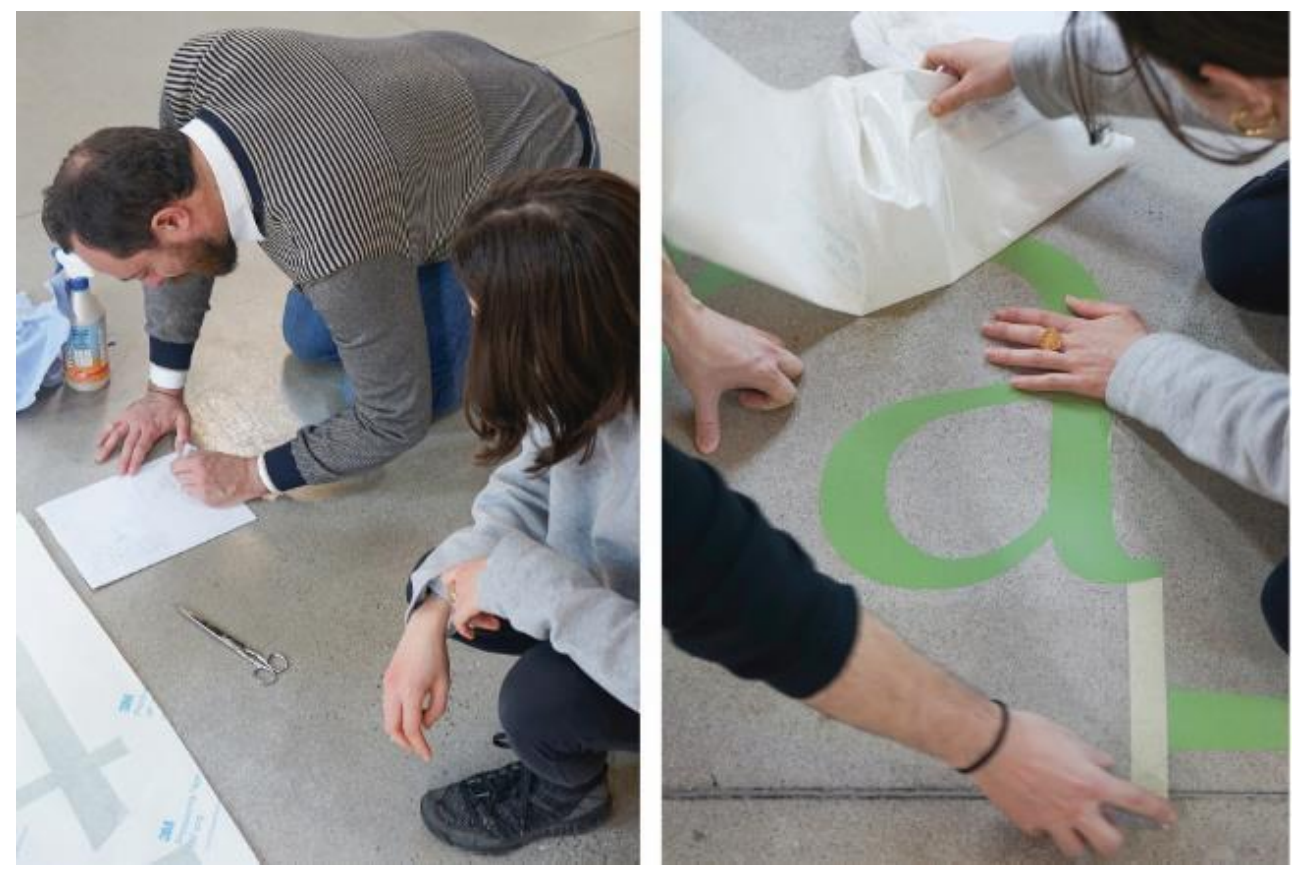

Figure 2. Teachers and students working to the exhibition Natura Naturata at the University of Ferrara (2019).

\subsection{Virtual exhibition}

Although Natura Naturata was open for only a short period the exhibition nevertheless enjoyed a considerable number of visitors who confirmed that they appreciated the choice of location, the exhibition itinerary, the graphic design supporting the narrative, and the exquisite books displayed. The positive response from the public would suggest that the exhibition should be continued, albeit virtually, so that those who did not get the chance to visit it can still enjoy the exhibition concepts and masterpieces of bookmaking. Our idea that we should continue along the path of a virtual - as well as a physical - exhibition was guided by the belief that it would be as an appropriate way of promoting the cultural heritage conserved by the University and would enable users to enjoy otherwise inaccessible works and documents without jeopardizing the work of protecting this heritage. Virtual exhibitions of this kind thus serve as an online archive of information relating to the physical exhibition, 
with the added advantage of being accessible from mobile devices (Irace, 2013). We chose the open-source MOVIO Content Management System as the means of creating our virtual exhibition. We can consider MOVIO as a toolkit because not only it is open-source software, but also a set of tools and services such as CMS MOVIO for iPhone, Android and tablet smartphones, including an app for the most popular mobile platforms, online tutorials, and one-to-one training on how to use the kit. The virtual exhibition is nearing its end and presents a special opportunity to give a breakdown of teaching methodology at the University of Ferrara as it was conceived and created in collaboration between the teachers of the Industrial Product Design Course and graduates who are recipients of collaboration contracts for research projects and post-graduate training internships. This will be accompanied by interactive content such as the stages in the construction and fitting-out of the exhibition, the museum space and the exhibition itinerary, together with the digitized images of the rare books and photos of the inauguration and visitors. Informational and graphical contents of the panels and captions in the display cases will also be made available, together with the press coverage of the event and the analysis done using a variety of tools to assess how well received the exhibition has been.

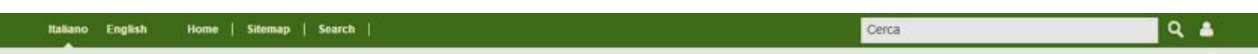

\section{Natura Naturata}

Capolavori librari dell'Università degli Studi di Ferrara

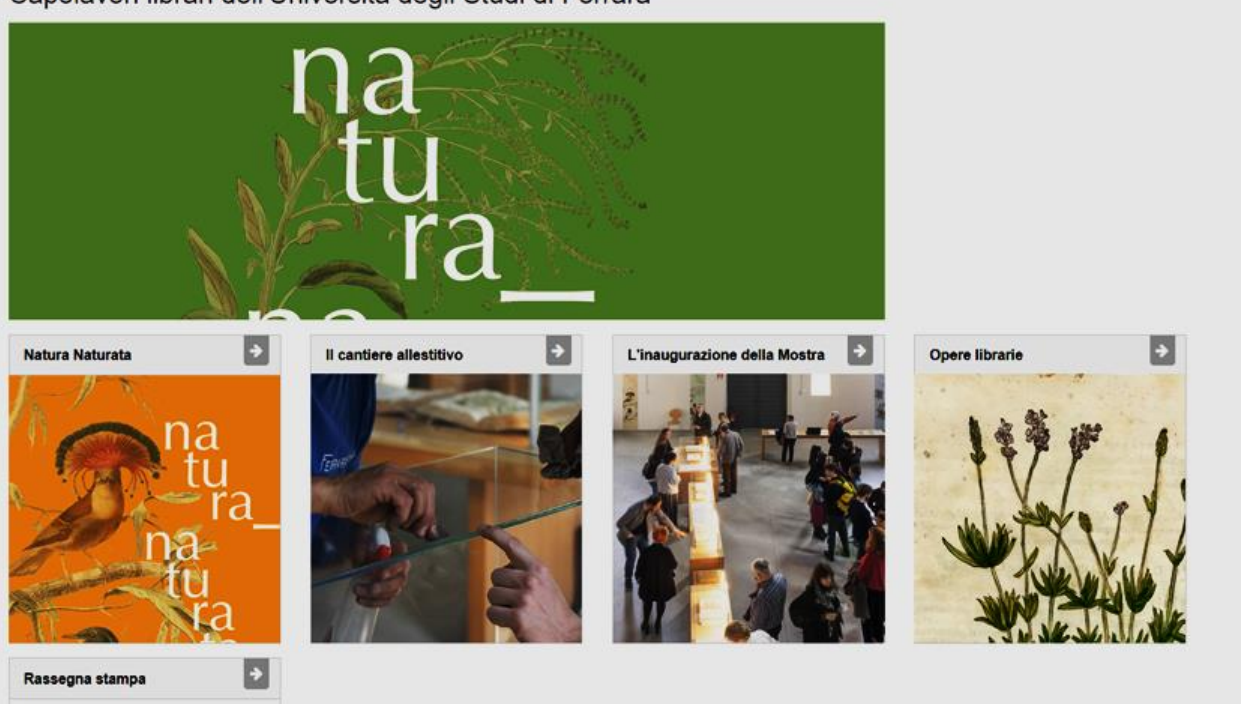

Figure 3. Natura Naturata virtual exhibition of the University of Ferrara on MOVIO (2019). 


\section{Impact and assessment of teaching and public engagement mission}

The attempt to determine impact was based on quantitative and qualitative data collected through headcount of visitors, a paper visitors' book located at the entrance of the exhibit, an online survey and observation. The assessment tools aimed to identify the reached audiences and verify the fulfillment of the project's goals (raising of awareness on the University of Ferrara libraries' heritage; exhibition's effectiveness in communicating educational contents; audience satisfaction). The results of headcount were satisfactory, since this was the first exhibit of its kind ever held by the University of Ferrara libraries, which had no established reputation for its bibliographic heritage. The visitors' book was signed by $33.5 \%$ of visitors and some of them also wrote comments, generally positive and marking the project's originality, as well as the students' and teachers' commitment and hard work. The venue itself and the displayed books also received strong approbation. The survey was divided into two sections: the first one regarded exhibition contents, event marketing, and customer satisfaction; the second one tried to identify the reached audiences. $31.6 \%$ of visitors completed the survey: they belonged to different audiences, ranging from those who had little $(33 \%)$ to those who had a considerable $(4 \%)$ knowledge of rare books. Most respondents thought the displays created by the students with their teachers were effective (43\%) or very effective (57\%), thanks to the exhibition's linearity and the clear explanatory panels and book tags, also appreciated for their graphic design. Several comments underlined the professional enrichment the students gained from the experience in a real-life context. $77.4 \%$ of respondents lived in the Ferrara area, so we can assume that the initiative was beneficial for the cultural development of the local community in which the University is located. To assess the impact on the participating students, the librarians also considered the observed evidence, as suggested by ISO 16439. No doubt that the students enjoyed the workshops in the libraries, where they could interact with their outstanding bibliographic heritage, realizing its great value. Moreover, feedback collected through student's spontaneous comments was largely positive. We are particularly proud of this learning experience, of the knowledge acquired by the students "rediscovering" an aesthetic and cultural treasure. They became witnesses of a shared (and so consolidated) institutional identity, and this way they created an exhibition itinerary for different audiences, thereby acquiring the specialist skills of bibliographic exhibition designers. At the same time citizens could find out more about the University's cultural heritage and teaching activity - and no doubt this was a great Third Mission result ${ }^{1}$.

\footnotetext{
${ }^{1}$ The paper is the result of a joint research and reflection by the authors. Paragraphs 1 and 3 are written by M. Contarini, 4.1 by D. Turrini, 4.2 by M. Manfra, 5 by A. Bernabè, paragraph 2 is the result of a joint writing by the authors.
} 


\section{References}

Bernabè, A., Tinti P. (2020). Universities, Third Mission and academic libraries' heritage. Towards an assessment scheme, "JLIS.it", 11, 1, pp. 56-72, DOI: 10.4403/jlis.it-12588.

Cassella, M., Madonna, N. (2019). Academic and research libraries. Third Mission between experience of practice and theory (CNR, Rome, 9 April 2019), "Bibliothecae.it", 8, 1, pp. 285-308, DOI: 10.6092/issn.2283-9364/9507.

Dal Buono, V., Trincherini, E. Turrini, D. (Eds.) (2019). Natura Naturata. Capolavori librari dell'Università degli Studi di Ferrara [text in Italian]. Ferrara, UnifePress.

Irace, F., (Ed.) (2013). Design \& cultural heritage. Intangible, virtual, interactive [text in Italian and English]. Milano, Electa.

ISO 16439 (2014). International Standard ISO 16439: information and documentation methods and procedures for assessing the impact of libraries, Geneve, Switzerland, ISO.

Lupo, E., (2008). La valorizzazione dei beni culturali come processo di design: casi, metodologie, strumenti [text in Italian]. Milano, Edizioni DPA-Politecnico di Milano.

Ministero per i Beni e le Attività Culturali (2004), Codice dei Beni Culturali e del Paesaggio. (D.lgs.42/2004 e successive modificazioni), art.6, c.1 [text in Italian]. Retrieved from https://www.gazzettaufficiale.it/eli/id/2014/08/08/14G00124/sg

Sabba F. (2019). Third Mission, communication, and academic libraries, "Bibliothecae.it", 8, 2, pp. 219-254, DOI: 10.6092/issn.2283-9364/10368.

Università degli Studi di Ferrara (2019). Università degli Studi di Ferrara. Sistema Bibliotecario di Ateneo. Retrieved from http://sba.unife.it/ 